\title{
Herniation of a hamartomatous growth of the liver in an infant masquerading as a cardiac tumour
}

\author{
VP Wickramasinghe ${ }^{1}$, MVC de Silva ${ }^{2}$ and SP Lamabadusuriya ${ }^{1}$
}

\section{Introduction}

Congenital diaphragmatic hernia is a common birth defect. The incidence varies from 1 in 5000 live births to 1 in 2000, if stillbirths are included. Herniation through the diaphragm could occur through the oesophageal hiatus, the left or right foramen of Bochdalek, the foramen of Morgagni, and communications caused by congenital absence of the left diaphragm or the central tendon [2]. They commonly occur on the left side (75-80\%) and occasionally bilaterally [1]. We report an unusual right-sided diaphragmatic hernia, occurring through the central tendon which was initially misdiagnosed as a cardiac tumour.

\section{Case history}

A baby girl was born vaginally to non-consanguineous parents as 38 weeks of gestation. Birthweight was $2.3 \mathrm{~kg}$. There was no perinatal complication but she had dysmorphic features comprising microcephaly (OFC $31 \mathrm{~cm}$; <3rd centile; NCHS 2000), polydactyly, cutis aplasia and low set abnormal ears. The cardiovascular system and abdomen were clinically normal. She developed jaundice and shortness of breath on the third day and was admitted to hospital. Serum bilirubin was below phototherapy level and other investigations excluded septicaemia. 2D- echocardiography showed hypertrophy of both ventricles with mild systolic dysfunction. Based on echocardiography a diagnosis of mild infiltrative cardiomyopathy was made. She was discharged at the age of 7 days, awaiting the report on karyotyping (karyotyping was normal).

At 10 weeks of age, the child was readmitted with the complaints of peripheral cyanosis and dyspnoea. She was restless. The weight was $3.5 \mathrm{~kg}$; OFC was $34 \mathrm{~cm}$ ( $<3$ rd centile; NCHS 2000). Early clubbing was present. A hypopigmented skin lesion was noted on the chest. Cardiovascular system was clinically normal. Repeat echocardiography revealed a small osteum secondum ASD. Biventricular hypertrophy and a moderate sized pericardial effusion was seen. A large tumour like mass was seen on the right side of the pericardial cavity, measuring about $3.5 \mathrm{~cm} \times 2.5 \mathrm{~cm}$. CT scan of the thorax was done and a mass lesion was confirmed. While in the ward the child developed generalised tonic seizures. A clinical diagnosis of tuberous sclerosis (TS) was made on the basis of seizures and the hypopigmented skin lesions. The cardiac tumour was presumed to be a

${ }^{1}$ Department of Paediatrics, ${ }^{2}$ Department of Pathology, Faculty of Medicine, University of Colombo, Sri Lanka. Correspondence: VPW, e-mail: <pujithaw@mail.ewisl.net> (Competing interests: none declared). Received 9 September 2005 and revised version accepted 31 January 2006. 


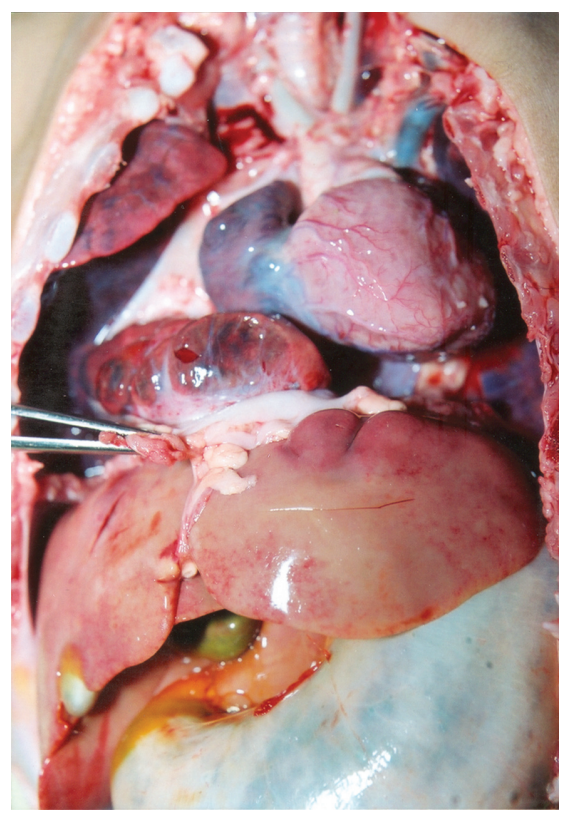

Figure 1. Position of the liver hamartoma in relation to thoracic and abdominal organs, revealed at necropsy examination.

rhabdhomyoma. Ultrasound scan (USS) of the brain was done. The echogenecity of the gyri appeared altered with focal ill-defined echogenic areas probably due to tubers. A CT scan of the brain did not detect any abnormalities. USS of the abdomen was done and renal tract abnormalities were excluded. Her cardiac function deteriorated and she died at the age of 12 weeks.

At necropsy a large outgrowth of the right lobe of the liver herniating through the diaphragm and pericardium was seen lying next to the right side of the heart (Figure 1) with a pericardial effusion. The heart was small, probably due to the pressure by the liver mass within the pericardial sac. There was an osteum secondum ASD. Kidneys were macroscopically normal. The outgrowth of the liver showed a few necrotic areas. The histology of the hepatic lesion showed that it was composed of normal liver tissue. Macroscopic examination and histology of brain did not reveal any evidence of TS. No significant pulmonary hypoplasia was noted.

\section{Discussion}

Herniation of the liver into the pericardial sac secondary to a defect in the central tendon is the rarest type of diaphragmatic hernia. A literature search revealed fourteen cases [2-9]. All were herniation of a lobe of the liver through the central tendon of the diaphragm into the pericardial sac. Usually they present soon after birth with respiratory distress. However, four cases presented between 1 and 12 month of life [2,9]. With the improvement in ultrasonographic techniques antenatal diagnosis has been possible $[3,6]$.

The present case could be the first in which, although the liver was in its normal anatomical position a hamartomatous growth originating from it had herniated through the central tendon into the pericardial sac. This would have grown gradually over time as the initial echo did not show an intrapericardial mass.

Initially, based on the clinical features of TS the mass lesion with the pericardium was diagnosed as a rhabdomyoma. Hamartomatous lesions of the liver are know to occur in patients with TS [10]. At necropsy, there were no pathological features suggestive of TS.

This case shows that it is important to include congenital disphragmatic hernia among the differential diagnosis of a pericardial mass associated with pericardial effusion detected on radiological imaging. It also emphasizes the fact that necropsy examination would help to discover unexpected pathologies, even in the presence of an apparent clinical cause of death.

\section{References}

1. Haslam RHA. Tuberous sclerosis, Neurocutaneous Syndromes. In Nelson Textbook of Paediatrics eds. Behrman R, Kliegman RM, Arvin AM. Prism Books Pvt Ltd. Bangalore, India. 1996; 15th Edition: 1707.

2. Thomsen G, Vesterdal J, Smith CCW. Diaphragmatic hernia into the pericardium. Acta Paediatrica 1954; 43: 485-92.

3. Stevens RL, Mathers A, Hollman AS, Mackenzie JR, Galea P, et al. An unusual hernia: congenital pericardial effusion associated with liver herniation into the pericardial sac. Pediatric Radiology 1996; 26: 791-3.

4. Collie DA, Turnbull CM, Shaw TR, Price WH. Case report: MRI appearances of left sided Morgagni hernia containing liver. British Journal of Radiology 1996; 278-80.

5. Davies MR, Oksenberg T, Da Fonseca JM. Massive foetal pericardiomegaly causing pulmonary hypoplasia, associated with intra-pericardial herniation of the liver. European Journal of Paediatric Surgery 1993; 3: 343-7.

6. Ake E, Fouron JC, Lessard M, Boisvert J, Grignon A, et al. In utero sonographic diagnosis of diaphragmatic hernia with hepatic protrusion into the pericardium mimicking an intrapericardial tumour. Prenatal Diagnosis 1991; 11: 719-24.

7. Skidmore MD, Morrison SC, Gauderer MW, Fanaroff AA. Imaging case of the month: II. Central diaphragmatic hernia with herniation of the liver into the pericardial sac. American Journal of Perinatology 1991; 8: $356-8$.

8. Einzig S, Munson DP, Singh S, Castaneda-Zuniga W, Amplatz K. Intrapericardial herniation of the liver: uncommon cause of massive pericardial effusion in neonates. American Journal of Roentgentology 1991; 8: 356-8.

9. Smith L, Lippert KM. Peritonio-pericardial diaphragmatic hernia. Annals of Surgery 1958; 148: 798-804.

10. Jozwiak S, Pedich M, Rajszys P, Michalowjcz R. Incidence of hepatic hamartomas in tuberous sclerosis. Archives of Diseases in Childhood 1992; 67: 1363-5. 